\title{
Study on drug related problems in tuberculosis patients undergoing treatment
}

\author{
G. Ranjani ${ }^{1 *}$, Sabushimitse Evariste ${ }^{1}$, Guru Prasad Mohanta ${ }^{1}$, N. Paari ${ }^{2}$
}

${ }^{1}$ Department of Pharmacy, Annamalai University, Tamil Nadu, India

${ }^{2}$ Department of Medicine, Rajah Muthiah Medical College Hospital, Tamil Nadu, India

Received: 07 June 2020

Revised: 10 July 2020

Accepted: 13 July 2020

\section{*Correspondence:}

Dr. G. Ranjani,

Email: ranjanipcp10@gmail.com

Copyright: (c) the author(s), publisher and licensee Medip Academy. This is an open-access article distributed under the terms of the Creative Commons Attribution Non-Commercial License, which permits unrestricted non-commercial use, distribution, and reproduction in any medium, provided the original work is properly cited.

\begin{abstract}
Background: Tuberculosis is a chronic infectious disease caused by Mycobacterium tuberculosis. It is one of the leading causes of mortality and morbidity around the world. The aim of this study to identify and document the drug related problems in tuberculosis patients under anti-tubercular treatment (ATT) in an attempt to promote adherence, reduce the drug related problems and improve success rate in TB treatment. The main objective of the study to identify the drug related problems in tuberculosis patients on ATT and second objective measure the medication adherence and counsel patients to improve medication adherence.

Methods: A prospective observational study was conducted in Raja Muthiah Medical College Hospital for 6 months from November 2018 to April 2019. The study was approved by Institutional Human Ethics Committee (IHEC).

Results: Total 101 drug related problems have been identified in 70 patients using pharmaceutical care network of Europe classification. Drug interactions $41.58 \%$ was the most common drug related problems found, which was clinically significant in tuberculosis patients with co- morbidities. Insufficient awareness of health and disease $21.75 \%$ was the second most common drug related problems found, $16.83 \%$ drug choice problems found. Nearly $64 \%$ of the enrolled patients were found to be non-adherence during pre-patient counselling. After the patient counselling the adherent rate was improved $74 \%$.

Conclusions: The study concludes that pharmacist provided patient counselling found to have significant influence on improvement in the patient's knowledge towards their disease and medication, and adherence to prescribed therapy which helps to improve the clinical outcome of TB patients.
\end{abstract}

Keywords: Drug related problem, Drug interaction, Medication adherence, Tuberculosis, Patient counselling

\section{INTRODUCTION}

Tuberculosis (TB) is a chronic granulomatous disease and a major health problem in developing countries. About $1 / 3^{\text {rd }}$ of the world's population is infected with Mycobacterium tuberculosis, out of which $10-15 \%$ develop the disease over their life time. As per WHO statistics for 2014 there were 9.6 million new TB cases globally, to which India was the highest contributor with
2.2 million cases. India has the dubious distinction of being the highest TB burden country for the past many years. ${ }^{1}$ Drug related problems are one kind of problem that appears in the using of the drugs or medicine therapy which was potentially or actual can influence the outcomes of the patient therapy, it's increasing the caring cost and also can block the attained of the therapy purposed. In order to improve the rational use of drugs, the pharmacist have an important role in identifying and 
solving the problems which has correlation with the use of drugs and potential or actual drug related problems (DRPs). Medication adherence is defined as the extent to which a patient's medication-taking behaviour coincides with the intension of the health advice he or she been given. Medication adherence is one of the most important factors that determine therapeutic outcome, especially in patients suffering from chronic illness. Adherence is also defined by World Health Organization as the degree to which the person's behaviour corresponds with the agreed recommendations from a health care provider. ${ }^{2}$

The main objective of the study to identify the drug related problems in tuberculosis patients on ATT and second objective measure the medication adherence and counsel patients to improve medication adherence.

\section{METHODS}

\section{Study design}

The prospective observational study was carried out from November 2018 to April 2019 in Rajah Muthiah Medical College and Hospital, Annamalai University, Tamil Nadu. The study was approved by Institutional Human Ethics Committee (approval letter no IHEC/0398/2018).

\section{Inclusion criteria}

Inclusion criteria were tuberculosis patients of all age groups, with or without co-morbidities, who are undergoing anti-tubercular treatment (newly diagnosed and previously treated) according to revised national tuberculosis control program (RNTCP) guidelines.

\section{Exclusion criteria}

Exclusion criteria pregnant and lactating women, treatment completed patients, mentally ill persons, and subjects not willing to participate.

\section{Study procedure}

Informed consents were obtained from the patients prior starting the study. Data was collected from the total of 70 patients, who visited the department of Medicine and DOTs centre with tuberculosis during the study period. The data collection form was designed to collect the required demographic and clinical data of the patients. The data collection form contains particulars like name of patient, IPIOP No, age, medication history, present illness of the patient, category of drug and therapeutic management and treatment details. The patient demographics collected from patient case sheets and recorded into data collection forms. Collected data related to drugs prescribed, dose, duration etc., by observing the medication records of the enrolled patients. Found out the drug related issues and brought to the physician's attention. Analyzed the drug related problems by using micro-medex and various text books along with interview from patients and evaluated as per PCNE classification. Adverse effect was documented using the form of national pharmacovigilance program. Medication adherence measured by using MAR scale. Counseled the patients-sensitizing them on need of medication adherence and using them to complete the course. Treatment outcome was measured.

\section{Statistical analysis}

Descriptive analysis was performed using microsoft excel and word 2007. For descriptive statistics, results were expressed in terms of percentage and presented using tables and diagrams according to the types of tool used.

\section{RESULTS}

A total number of 70 patients were enrolled in our study. All enrolled patients completed the study. The upcoming results were taken from the patients who successfully completed the study.

Table 1: Demographics of patients.

\begin{tabular}{|c|c|c|}
\hline Characteristics & No. of patients & $\%$ \\
\hline \multicolumn{3}{|l|}{ Gender } \\
\hline Male & 46 & 65.71 \\
\hline Female & 24 & 34.28 \\
\hline \multicolumn{3}{|l|}{ Age distribution } \\
\hline Pediatrics & 3 & 4.28 \\
\hline Adults & 56 & 80 \\
\hline Elderly & 11 & 15.71 \\
\hline \multicolumn{3}{|l|}{ Comorbidities } \\
\hline $\begin{array}{l}\text { With co- } \\
\text { morbidities }\end{array}$ & 30 & 42.85 \\
\hline $\begin{array}{l}\text { Without co- } \\
\text { morbidities }\end{array}$ & 40 & 57.14 \\
\hline \multicolumn{3}{|c|}{ Family history of TB } \\
\hline Yes & 39 & 55.71 \\
\hline No & 31 & 44.28 \\
\hline \multicolumn{3}{|l|}{ Types of TB case } \\
\hline New & 53 & 75.71 \\
\hline Previously treated & 17 & 24.28 \\
\hline \multicolumn{3}{|l|}{ Social habits } \\
\hline Smoker & 5 & 7.14 \\
\hline Alcoholic & 9 & 12.85 \\
\hline $\begin{array}{l}\text { Smoker and } \\
\text { alcoholic }\end{array}$ & 25 & 35.71 \\
\hline No social habits & 31 & 44.28 \\
\hline
\end{tabular}

\section{Medication adherence}

Medication adherence to anti-TB treatment is a major determinant of treatment outcome. Medication adherence measured by using MAR scale. 
Table 2: Drug related problems (PCNE).

\begin{tabular}{|c|c|c|c|}
\hline Code & Problems & $\begin{array}{l}\text { No. of } \\
\text { problems }\end{array}$ & Percentage \\
\hline P1 & Adverse drug reaction & 11 & 10.89 \\
\hline $\mathbf{P 2}$ & Drug choice problems & 17 & 16.83 \\
\hline P2.1 & $\begin{array}{l}\text { Duplication of } \\
\text { therapeutic group }\end{array}$ & 5 & 4.95 \\
\hline P2.2 & $\begin{array}{l}\text { Inappropriate drug } \\
\text { form }\end{array}$ & 7 & 6.93 \\
\hline P2.3 & $\begin{array}{l}\text { No clear indication of } \\
\text { drug }\end{array}$ & 5 & 4.95 \\
\hline P3 & Drug use problems & & \\
\hline P3.1 & $\begin{array}{l}\text { Drug overused/ over- } \\
\text { administered }\end{array}$ & 9 & 8.9 \\
\hline P4 & Drug interaction & 42 & 41.58 \\
\hline P5 & Others & & \\
\hline P5.1 & $\begin{array}{l}\text { Insufficient awareness } \\
\text { of health } \\
\text { and diseases }\end{array}$ & 22 & 21.75 \\
\hline
\end{tabular}

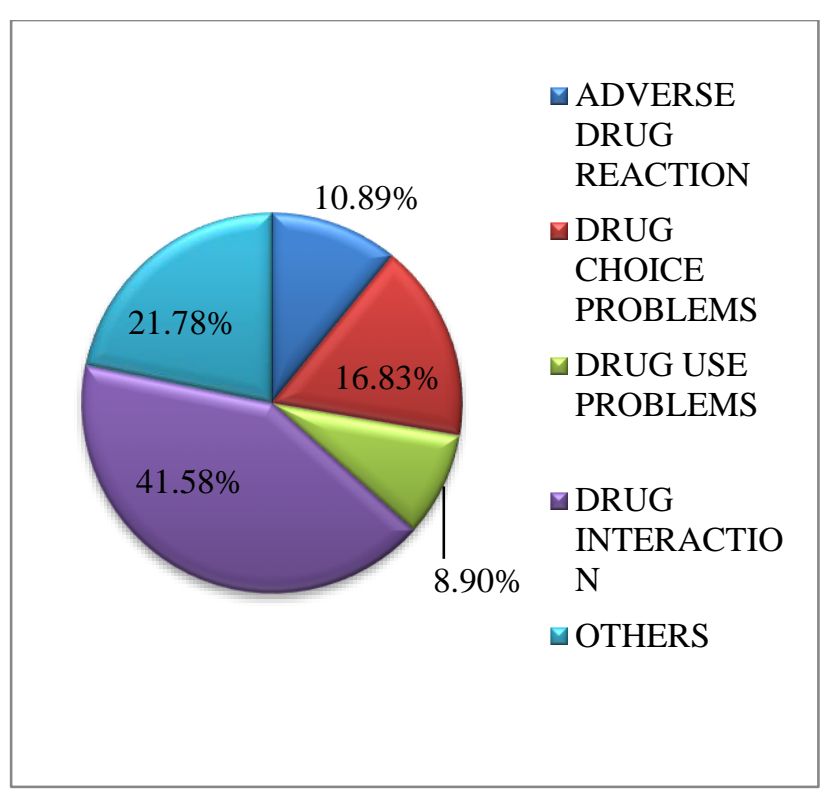

Figure 1: DRPs classification.

Table 3: Detailed drug related problems.

\begin{tabular}{|c|c|c|c|c|c|c|c|}
\hline \multicolumn{8}{|c|}{ P1 Adverse drug reaction } \\
\hline S. no. & Drugs & ADR & \multicolumn{2}{|c|}{ Causality assessment } & \multicolumn{3}{|c|}{ No. of cases } \\
\hline 1 & $\mathrm{H}, \mathrm{R}$ and $\mathrm{Z}$ & Gastritis & \multicolumn{2}{|l|}{ Probable } & \multicolumn{3}{|l|}{7} \\
\hline 2 & $\mathrm{H}, \mathrm{R}$ and $\mathrm{Z}$ & Gastritis with anemia & \multicolumn{2}{|l|}{ Probable } & \multicolumn{3}{|l|}{1} \\
\hline 3 & $\mathrm{H}, \mathrm{R}$ and $\mathrm{Z}$ & Anemia & \multicolumn{2}{|l|}{ Probable } & \multicolumn{3}{|l|}{1} \\
\hline 4 & $\mathrm{H}$ and $\mathrm{E}$ & Flu like symptoms & \multicolumn{2}{|l|}{ Probable } & \multicolumn{3}{|l|}{1} \\
\hline 5 & $\mathrm{H}, \mathrm{R}, \mathrm{Z}$ and $\mathrm{E}$ & Itching and rashes & Probable & & \multicolumn{3}{|l|}{1} \\
\hline \multicolumn{8}{|c|}{ P2 Drug choice problems } \\
\hline \multicolumn{8}{|c|}{ P2.1 Duplication of therapeutic group } \\
\hline S. no. & Drugs & Therapeutic group & Classification & \multicolumn{3}{|c|}{$\begin{array}{l}\text { Consequence of drug } \\
\text { duplication }\end{array}$} & $\begin{array}{l}\text { No. of } \\
\text { case }\end{array}$ \\
\hline 1 & Injection amikacin & Injection streptomycin & Aminoglycoside & \multicolumn{3}{|c|}{ Amikacin was stopped } & 1 \\
\hline 2 & Injection pantoprazole & T. rabeprazole & PPI & \multicolumn{3}{|c|}{ Rabeprazole was stopped } & 1 \\
\hline 3 & Formoterol (inhaler) & Salbutamol & Bronchodilators & \multicolumn{3}{|c|}{ Formoterol was stopped } & 1 \\
\hline 4 & Injection streptomycin & Injection gentamicin & Aminoglycoside & \multicolumn{3}{|c|}{ Gentamicin was stopped } & 1 \\
\hline 5 & $\begin{array}{l}\text { Budesonide and } \\
\text { formoterol }\end{array}$ & Fluticasone & Corticosteroids & \multicolumn{3}{|c|}{ Budesonide was stopped } & 1 \\
\hline \multicolumn{8}{|c|}{ P2.2 Inappropriate drug form } \\
\hline S. no. & Drug dosage from & $\begin{array}{l}\text { Appropriate dosage } \\
\text { form }\end{array}$ & \multicolumn{3}{|c|}{$\begin{array}{l}\text { Consequence of inappropriate drug } \\
\text { form }\end{array}$} & \multicolumn{2}{|c|}{ No. of cases } \\
\hline 1 & Injection pantoprazole & Oral tablet & \multicolumn{3}{|c|}{$\begin{array}{l}\text { Informed to the physician then injection } \\
\text { pantoprazole changed to tab pantoprazole }\end{array}$} & 6 & \\
\hline 2 & Injection ranitidine & Oral tablet & \multicolumn{3}{|c|}{$\begin{array}{l}\text { Informed to physician then changed to tab } \\
\text { ranitidine }\end{array}$} & 1 & \\
\hline \multicolumn{8}{|c|}{ P2.3 No clear indication of drug } \\
\hline S. no. & Drugs & Indication & \multicolumn{3}{|c|}{ Inappropriate use } & \multicolumn{2}{|c|}{ No. of cases } \\
\hline 1 & Chlorpromazine & Psychotic disorder & \multicolumn{3}{|c|}{ Patient does not have these symptoms } & \multicolumn{2}{|c|}{1} \\
\hline 2 & Pantoprazole & Gastric ulcer/GERD & \multicolumn{3}{|c|}{ Patient does not have these symptoms } & 4 & \\
\hline 3 & Ranitidine & Gastric ulcer/GERD & Patient does not $\mathrm{h}$ & ve the & & 1 & \\
\hline P3 Dr & use problems & & & & & & \\
\hline P3.1 D & g overused/over-admi & & & & & & \\
\hline S. no. & Problem & & Intervention & & & & of cases \\
\hline 1 & Patient taking drug too & g period & Patient counsellin & & & 9 & \\
\hline
\end{tabular}


Table 3: Drug interactions (moderate) (ATT with concomitant drugs).

\begin{tabular}{|c|c|c|c|c|}
\hline S. no. & Interacting drugs & \multicolumn{2}{|l|}{ Effect } & No. cases \\
\hline 1 & Streptomycin and cefotaxime & \multicolumn{2}{|c|}{ Increased risk nephrotoxicity } & 2 \\
\hline 2 & Streptomycin and amikacin & \multicolumn{2}{|c|}{ Increased risk nephrotoxicity and ototoxicity } & 1 \\
\hline 3 & Rifampicin and antacid & \multicolumn{2}{|c|}{ Decrease the rifampicin absorption } & 2 \\
\hline 4 & Isoniazid and paracetamol & \multicolumn{2}{|c|}{$\begin{array}{l}\text { Increase the paracetamol toxicity }(\mathrm{H}) \text { Inhibit paracetamol } \\
\text { metabolism }\end{array}$} & 7 \\
\hline 5 & Isoniazid and phenytoin & \multicolumn{2}{|c|}{ Decrease the phenytoin concentration } & 2 \\
\hline 6 & Streptomycin and ceftriaxone & \multicolumn{2}{|c|}{ Increased risk of nephrotoxicity } & 2 \\
\hline 7 & Isoniazid and prednisolone & \multicolumn{2}{|c|}{ Decrease the effect of isoniazid } & 1 \\
\hline \multicolumn{5}{|c|}{$\begin{array}{l}\text { Clinically significant drug interactions (moderate/potential) of ATT drugs with hypertensive drugs and diabetic } \\
\text { drugs }\end{array}$} \\
\hline S. no. & Interacting drugs & Effect & Intervention & No. of cases \\
\hline 1 & Rifampicin and nifedipine & $\begin{array}{l}\text { Decrease the anti- } \\
\text { hypertensive effect }\end{array}$ & $\begin{array}{l}\text { Monitor BP } \\
\text { dose adjustment }\end{array}$ & 5 \\
\hline 2 & Rifampicin and enalapril & $\begin{array}{l}\text { Decrease the anti- } \\
\text { hypertensive effect }\end{array}$ & $\begin{array}{l}\text { Monitor BP } \\
\text { dose adjustment }\end{array}$ & 2 \\
\hline 3 & Rifampicin and losartan & $\begin{array}{l}\text { Decrease the anti- } \\
\text { hypertensive effect }\end{array}$ & $\begin{array}{l}\text { Monitor BP } \\
\text { dose adjustment }\end{array}$ & 3 \\
\hline 4 & $\begin{array}{l}\text { Isoniazid and metformin (oral } \\
\text { anti-diabetics) }\end{array}$ & $\begin{array}{l}\text { Interfere with glucose } \\
\text { control }\end{array}$ & Monitor glucose level & 9 \\
\hline 5 & Isoniazid and insulin & $\begin{array}{l}\text { Interfere with glucose } \\
\text { control }\end{array}$ & Monitor glucose level & 6 \\
\hline
\end{tabular}

H - Isoniazid, R - Rifampicin, Z - Pyrazinamide, E - Ethambutol, PPI - Proton pump inhibitors and GERD - Gastroesophageal reflux disease.

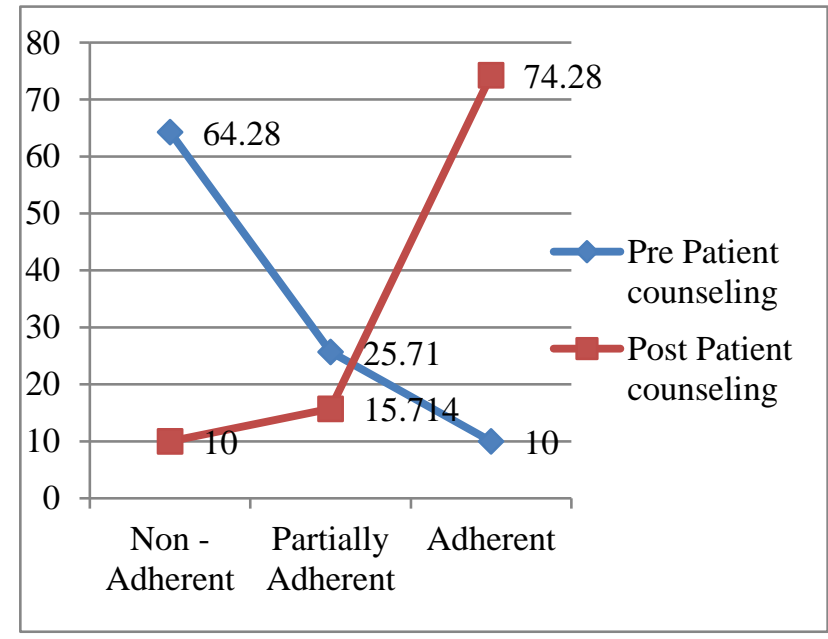

Figure 2: Medication adherence score.

\section{DISCUSSION}

The gender distribution of study population showed that among 70 patients, $65.71 \%$ were male and $34.28 \%$ were female. This data showed that males are at more risk to get infection than female patient; this similar result shows many studies. ${ }^{3,5,6,9}$ In this study shows more adult people were exposed to risk factorslinfections compared to elderly and children this result was similar to the other studies. $^{3,10}$ The present study shows without co morbidities patient was more than with co morbidities patient, another study shows more no of TB with co morbidities patients. ${ }^{6}$ In this study shows patients with family history of TB was found more as compared to No family history TB, Krishna et al shows similar results but another study result patients are mostly in no family history of TB. ${ }^{3,10}$ More no of newly treated TB patients in present study, these similar study result showed by Shivaraj et al and Krishna et al. ${ }^{3,10}$ Study result shows more no smoker and alcoholic patients affect with TB, Fei et al shows less no of TB patient had smoking and alcoholic habits. ${ }^{6}$ A substantial proportion of hospitalized patients experience medication-related problem that is preventable. Total 101 DRPS have been identified in 70 patients. The present study shows more number of DRPs occurred in TB patients with co-morbidities $43 \%$ as compared to TB alone, as similar to the study conducted by Raj et al shows DRPs in TB patients with co morbidities are more due to drug interactions of ATT with concomitant drugs which are clinically significant in case of hepatic impairment, DM. COPD, and hypertension. ${ }^{3}$ Gastritis was found to be the most frequent ADR by anti-tubercular drugs in the present study. Some study shows gastritis most common ADR with intake of anti TB drugs. 5,6,8 Anemia, flu like syndrome and itching was less in the study. Total $16.83 \%$ DCP were identified in the study, another study shows more no of DCP; they are studied in more sample size. ${ }^{3}$ This study found to be $4.95 \%$ of no clear indication of drug used. $19.05 \%$ drugs used without indication; this result studied by Ramatillah et al. $^{7}$ Study found to be $4.95 \%$ of duplication of therapeutic group and $6.93 \%$ inappropriate drug form. Similar result by Shivaraj et al. ${ }^{3} 8.9 \%$ drug use problems identified due to drug overused/over administered. $1.8 \%$ 
overdose of drug dose problem studied. ${ }^{8}$ In this study, a total of $41.58 \%$ drug interactions were found shown in (Table 2 and 3). Drug-drug interactions having significant impact on TB patients with co-morbid disease conditions like DM, hypertension and COPD etc. were the chronic illness patients on regular medications. Management of DM in TB should be aggressive. The efficacy of insulin and other anti-diabetic agents may be diminished by isoniazid. ${ }^{4}$ Caution is advised when anti diabetics drugs prescribed for DM with TB patients. Clinical monitoring is recommended following initiation or discontinuation of anti-diabetic drugs, and the dosages of concomitant antidiabetic agents adjusted as necessary. In this study $21.78 \%$ patients showed insufficient awareness of health and disease as it comes under "others" category of DRPs. Patients are discriminated by using separate utensils for food or drink due to the misapprehension about transmission of disease. Increase anxiety/tension, fear of loss of wage/earning, and stigma threatening self-esteem and quality of life are associated with diagnosis of TB. Psychosocial reactions towards TB as divulged in this study should be addressed through counselling and communication during treatment in the DOTS centre. These may contribute the success rate of TB control program. ${ }^{3,10}$ Non adherent $24.7 \%$ less in this study. ${ }^{9}$ Present study shows $64.28 \%$ of non-adherent. Adherent rate was improved by patient counselling shown in Figure 2. The present study assessed the impact of pharmacist assisted patient counselling in improving medication adherence in TB patients. Non-adherence can affect the success rate of TB treatment. Reason identified for nonadherence. In the present study, the main reason for nonadherence forgetting to take medication, physical difficulty, social habits, lack of support from family and friends, co-morbidity, side effects. These problems of the non-adherence would be reduced by good communication between the patient and health provider as well as by patient counselling. The similar findings were observed in the study conducted by Krishna et al shows pharmacist assisted patient counselling had a statistically significant impact in improving medication adherence and QOL in TB patients. ${ }^{10}$

\section{CONCLUSION}

The study concludes that pharmacist provided patient counselling found to have significant influence on improvement in the patient's knowledge towards their disease and medication, and adherence to prescribed therapy which helps to improve the clinical outcome of TB patients. The study shows necessity of clinical pharmacy service in health care system. Clinical pharmacist work directly with physician, other healthcare professionals, and patients to ensure that the medications prescribed for patients contribute to the best possible health outcomes.

Funding: No funding sources

Conflict of interest: None declared

Ethical approval: The study was approved by Institutional Human Ethics Committee (IHEC/0398/2018)

\section{REFERENCES}

1. KD Tripathi essential of medical pharmacology. 8th ed. Jaypee; 2020:815

2. Nyfort K, Nahata M. A Textbook of clinical pharmacy practice. 2nd ed. orient blackswan; 2020.

3. Shivaraj G, Muralikrishnan, Nijeesh. study on drug related problems in tuberculosis patients with co morbidities in a tertiary care teaching hospital. EJPMR. 2017;4(9):756-67.

4. Karen Baxter, Stockley's Drug Interactions, 8th Edition, Page. No: 7-388, RPS Publishing.

5. Farazi A, Sofian M, Jabbariasl M. Adverse reactions to antituberculosis drugs in Iranian tuberculosis patients. Tuberculosis research and treatment; 2014.

6. Fei CM, Zainal H, Ali I, Ali H. Evaluation of adverse drug reactions induced by anti-tuberculosis drugs in hospital pulau pinang. Malays J Med Sci. 2018;25(5):103-14.

7. Ramatillah DL, Nongkanga N, Suhartini S. Studied evaluation of drug related problems of the tuberculosis patients at the lung disease ward in installation of stayed caring of central general hospital persahabatan. World J Pharmaceutical Res. 2018;3(4):14-23.

8. Abrogoua D, Alexis B. Thierry kamenan, brou jean et al studied pharmaceutical interventions in the management of tuberculosis in a pneumophtisiology department, ivory coast, therapeutic and clinical risk management. Ther Clin Risk Manag. 2016;12:174956.

9. Gube AA, Debalkie M, Seid K, Kiberlem. Assesment of anti-TB drug nonadherence and associated factors among $\mathrm{Tb}$ patients attending $\mathrm{TB}$ clinics in Arba Minch government health institution. Tuberculosis Res Treatment. 2018:1-7.

10. Krishna GK, Ananthakrishnan S, Reddy T. Study on adherence to anti tuberculosis drugs under DOTs and Non-DOTs and factors affecting adherence. World J Pharmacy Pharmaceutical Sci. 2020;6(9):1973-86.

Cite this article as: Ranjani G, Evariste S, Mohanta GP, Paari N. Study on drug related problems in tuberculosis patients undergoing treatment. Int $\mathrm{J}$ Basic Clin Pharmacol 2020;9:1199-203. 